\title{
Optimal pump selection for variable speed operation in water distribution network
}

\section{Seleção otimizada de bombas para operação com rotação variável em redes de distribuição de água}

\author{
Débora Salomé Móller ${ }^{1}$ (D), Gustavo Meirelles Lima' ${ }^{1}$ (D), Bruno Melo Brentan ${ }^{1}$ (D) \& Daniel Bezerra Barros $^{1}$ (i) \\ ${ }^{1}$ Universidade Federal de Minas Gerais, Belo Horizonte, MG, Brasil \\ E-mails: deborasmoller@gmail.com (DSM), gustavo.meirelles@ehr.ufmg.br (GML), brentan@ehr.ufmg.br (BMB), danielbezerrab@gmail.com (DBB)
}

Received: June 17, 2020 - Revised: October 03, 2020 - Accepted: October 05, 2020

\begin{abstract}
The optimization of pumping stations operation in water distribution networks has been largely studied, especially with the development of speed drivers, which allowed the machines to adjust the hydraulic power inserted to the system according to the demand requirements. Although this approach results in high benefits, the original characteristics of pumps remains the same. Consequently, the pumps can be operating in a range of suboptimal efficiency. Thus, this paper will evaluate the benefits that an optimized pump selection can bring for variable speed operation. The selection of the pumps best efficiency point and the number of pumps operating in parallel are defined applying Particle Swarm Optimization (PSO) to minimize the energy costs of the system. For the case study, the results show that there is no benefit when more pumps are operated in parallel, and that a flexible operational routine significantly reduces the energy expenses, especially when the pump is selected for this purpose.
\end{abstract}

Keywords: Pumps; Best Efficiency Point; Water Distribution Network; Optimization.

\section{RESUMO}

A otimização da operação das estações elevatórias nas redes de distribuição de água tem sido amplamente estudada, principalmente com o desenvolvimento de conversores de frequência, que permitem que as máquinas ajustem a potência hidráulica de acordo com as demandas requeridas. Embora essa abordagem resulte em muitos benefícios, as características originais das bombas permanecem as mesmas. Consequentemente, as bombas podem estar operando em um intervalo de eficiência abaixo do ideial. Portanto, esse artigo irá avaliar os beneficios que a seleção otimizada de uma bomba pode gerar para sua operação com rotação variável. A seleção da bomba com o melhor ponto de operação e o número de bombas operando em paralelo na rede foram definidos através da técnica Particle Swarm Optimization (PSO), minimazando os custos de energia do sistema. Os resultados mostram que não há benefício em operar múltiplas bombas em paralelo, e que manter uma rotina operacional mais flexível reduz significativamente os gastos com energia, principalmente quando a bomba é selecionada com este objetivo.

Palavra-chave: Bomba; Melhor Ponto de Eficiência; Rede de Distribuição de Água; Otimização. 


\section{INTRODUCTION}

Pumping stations have a major role in Water Distribution Networks (WDNs), supplying consumers located far away and higher than the treatment station reservoir. From the supplier side, pumping stations represents one of the highest expenses of the process due to the energy consumption in these sites (Tarquin \& Dowdy, 1989; Jowitt \& Germanopoulos, 1992; Venkatesh \& Brattebø, 2011). Therefore, efficient equipment, pump and motors, and an efficient operational strategy, are important to reduce the operational costs.

To evaluate the performance of the machines, a great effort have been made by some governments and institutes, classifying the equipment according to its efficiency, allowing an easy and fast comparison among the products (Hydraulic Institute, 1994; American National Standards Institute, 1994; European Comission, 2003; International Electrotechnical Commision, 2008; Brasil, 2010). Despite this information, the selection of pumps remains a complex problem. The dynamic behavior of WDNs imposes different operation points, changing pumps efficiency, which can be far from its Best Efficiency Point (BEP), increasing the overall energy consumption.

Two main alternatives can be used to reduce the problem of a high drop in efficiency during the day. The first one is the use of multiple pumps in parallel, switching them on and off according to the demand. This procedure allows the pumps operating in a narrower range of efficiency, close to their BEP (Giacomello et al., 2013; Koor et al., 2014; Olszewski, 2016). The second option is the use of speed driver to adjust the pump speed according to the demand. This procedure not only maintains a high efficiency, but also reduces the power consumed (Hashemi et al., 2014; Brentan et al., 2018). Both options can also be combined to increase even more the pumping station efficiency.

However, the pump selection remains a problem: which parameters should be used? The maximum demand flow? The minimum demand flow? The more frequent flow? In a dynamic system like WDNs, the pump BEP not only affects its efficiency but the behavior of all components of the system, such as the water levels of tanks. This is an important parameter, since, during peak hours, where energy tariffs are higher, the WDN could be supplied only by the tanks, reducing the expenses at pumping stations (Walski, 1993; Boulos et al. 2001). Thus, a bigger pump may not be the most efficient through the day, but the possibility to turn it off during more expensive operation period, can lead to its economic feasibility.

As shown by Mala-Jetmarova et al. (2018) the pump optimization on WDNs is important to reduce operational costs, so it has been widely studied. Research on pump optimization focuses on three main variables: pump location, pump size and pump operation (Zhang et al., 2012; Tang et al., 2014; Brentan \& Luvizotto, 2014; Brentan et al., 2018)

The objective of this work is develop an optimization model that allows the analysis of the most economical and efficient alternatives for pumping, being the pump selection read as an optimization problem of minimizing energy costs. The Particle Swarm Optimization algorithm (PSO) is used to solve the problem. Three different cases are studied. The first one selects the pumps of the network operating in fix speed. The second case uses the pump selected in the first study and optimize its operation point using a speed driver. Finally, in the third case the pump BEP and rotational speed are jointly optimized. In addition, for each case the number of pumps operating in parallel is varied from one to three. A sensitivity analysis of energy tariffs is also made verifying the influence of the peak period in the pump selection.

\section{MATERIAL AND METHODS}

\section{Pumps characteristics}

The Brazilian National Institute of Metrology, Standards and Quality (Brasil, 2010) classified centrifugal pumps according to their efficiency in five categories. A total of 1,600 pumps are classified, and $346(21.6 \%)$ are set to the best group. However, the pumps characteristics (flow and head) of each group remains scattered. The specific speed of each pump (Equation 1) is calculated trying to identify correlation with its efficiency, as shown in Figure 1a. The results are not satisfactory $\left(\mathrm{R}^{2}=0.61\right)$, and a new correlation, using the flow is tried, as shown in Figure 1b. It can be observed a better agreement between the two variables for a logarithmic curve $\left(\mathrm{R}^{2}=0.82\right)$, and the resulting curve is shown

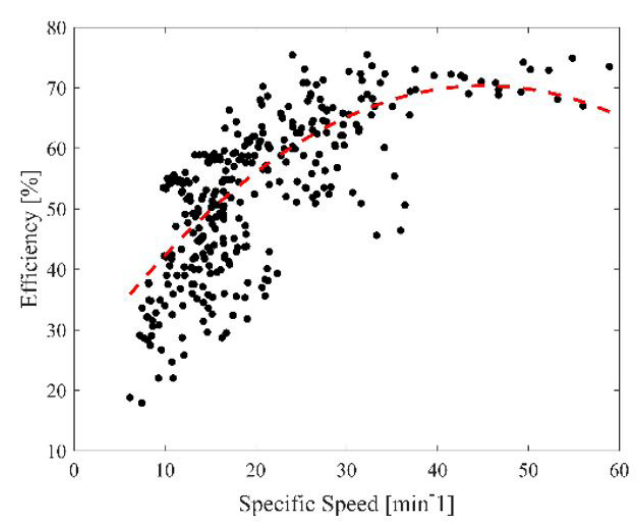

(a)

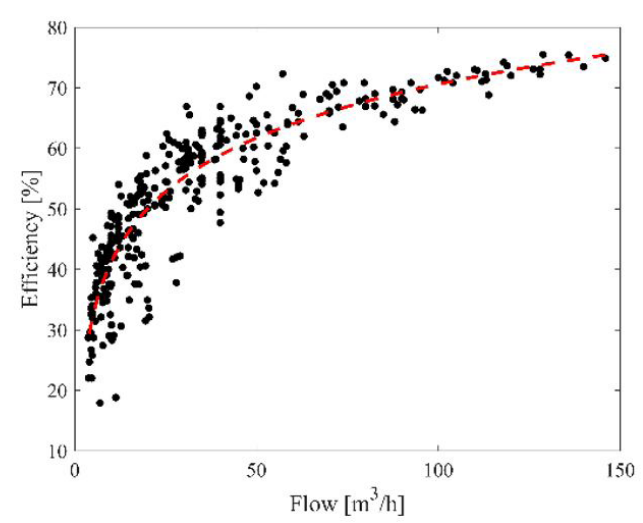

(b)

Figure 1. Relation between pumps efficiency and their characteristics: (a) Specific speed; (b) Flow. 
in Equation 2. A similar behavior is observed when the curve obtained in Figure 1b is compared with Equation 3, presented by Stoffel \& Lauer (1994) to estimate pumps efficiency available in the European market. This comparison points that the curve of Figure $1 \mathrm{~b}$ can be a good parameter to estimate pumps efficiency from Brazilian manufacturers.

$$
n_{s}=\frac{\sqrt{Q_{B E P}}}{\left(\frac{H_{B E P}}{z}\right)^{3 / 4}}
$$

$\eta=12.81 \cdot \ln \left(Q_{B E P}\right)+11.62$

$\eta=-11.48 \cdot\left[\ln \left(n_{s}\right)\right]^{2}-0.85 \cdot\left[\ln \left(Q_{B E P}\right)\right]^{2}-0.38 \cdot \ln \left(n_{s}\right) \cdot \ln \left(Q_{B E P}\right)+88.59 \cdot \ln \left(n_{s}\right)+13.46 \cdot \ln \left(Q_{B E P}\right)$

Where $N_{S}$ is the pump specific speed, $Q_{B E P}$ is the pump flow on its best efficiency point, $H_{B E P}$ is the pump head on its best efficiency point, $\eta$ is the pump efficiency.

\section{Pumps selection}

The selection of pumps for each case is defined through the minimization of the energy expenses of the system, aiming obtain the lowest operational cost. Considering the energy and power tariff values, the objective function can be written as Equation 4.

$$
F O=\sum_{p=l i=l}^{N_{p}} \sum^{24}\left[\frac{\gamma \cdot Q_{i} \cdot H_{i}}{1000 \cdot \eta_{i}} \cdot t_{e i}+P_{\text {máx }} \cdot t_{a i}\right]+P e n
$$

\section{where:}

FO [\$] - objective function to be minimized, describing the operational of a day;

$N_{p}$ [dimensionless] - number of pumps operating in the network;

$\gamma\left[N / m^{3}\right]$ - specific weight of water;

$Q_{i}\left[m^{3} / s\right]$ - pump flow at time $i$;

$H_{i}[m]$ - pump head at time $i$;

$\eta_{i}$ [dimensionless $]$ - pump efficiency at time $i$;

$t_{e i}[\$ / k W h]$ - energy tariff at time $i$;

$t_{a i}[\$ / k W]-$ power tariff at time $i$;

$P_{\operatorname{máx}}[k W]$ - maximum power;

$P e n[\$]-$ penalty function.

The penalty presented in Equation 4 is a way to handle the system constrains, resulting of the sum of the penalty functions presented in Equations 5-7. In an optimization processes it is extremely important the definition of the penalty coefficient $\beta$ used in Equations 5-7 to guarantee a feasible solution and a faster convergence (Manzi et al., 2018). The adopted value in this paper is $10^{18}$. The high value for $\beta$ is chosen to avoid the selection of pumps which violate any of restrictions. The water network should operate with pressures higher than the minimum operational pressure (Equation 5). In addition, there are also restrictions regarding the water levels of the tanks, as they cannot exceed the maximum value, and the initial and final water levels must be equal. (Equations 6 and 7).

$$
\begin{aligned}
& \operatorname{Pen}_{\text {p.min. }}=\sum_{i=0}^{n p e n} \beta \cdot\left|p_{\min }-p_{(j, i)}\right| \cdot \\
& \operatorname{Pen}_{\text {NAmax. }}=\sum_{i=0}^{n p e n} \beta \cdot\left|N A_{i}-N A_{\max }\right| \\
& \text { Pen }_{\text {NAfinal.initial. }}=\sum_{i=0}^{n p e n} \beta \cdot\left|N A_{\text {final }}-N A_{\text {initial }}\right|
\end{aligned}
$$

where:

$p_{\min }[m]$ - established minimum pressure;

$p_{j, i}[m]$ - node pressure $j$ in time $i$;

$N A_{\max }[m]$ - maximum water level tank;

$N A_{i}[m]$ - water level in the tank in time $i$;

$N A_{\text {final }}[\mathrm{m}]-$ tank water level at the end of simulation;

$N A_{\text {initial }}[m]-$ tank water level at the beginning of simulation.

The first step for selecting the pump is define the number of pumps to be installed, and in the sequence, create the head curve for the newly selected pump and calculate the maximum efficiency of each pump by Equation 2. On the second step, a hydraulic simulation is performed, followed by the calculation of energy costs. As previously described, there are hydraulic conditions that should be achieved. Thus, nodal pressure and tanks' level are analyzed to add a penalty to the final cost. Lastly, the convergency analysis is made, according to stop criteria defined, saving the result for a converged solution, or performing an additional iteration of the optimization process again. Figure 2 shows the following steps to achieve the best pump for each case studied.

The presented problem is solved through the optimization technique PSO, that has been used in Engineering, and as presented by Mala-Jetmarova et al. (2018), widely applied in Hydraulic Engineering, coupled with the hydraulic simulator Epanet (Rossman, 2000)

\section{Particle swarm optimization}

The PSO, as proposed by Eberhart \& Kennedy (1995), is a metaheuristic algorithm composed of a number of particles moving in a search space. These particles are influenced by the other particles of the group that performed better and their own knowledge. At each iteration, the particle position and speed are updated by Equations 8 and 9 .

$V_{i}^{k+1}=\omega \cdot V_{i}^{k}+c_{1} \cdot \operatorname{rand}_{1} \cdot \frac{\left(P_{i}^{k}-X_{i}^{k}\right)}{\Delta t}+c_{2} \cdot \operatorname{rand}_{2} \cdot \frac{\left(G-X_{i}^{k}\right)}{\Delta t}$

$X_{i}^{k+1}=X_{i}^{x}+V_{i}^{k+1} \cdot \Delta t$

where:

$V[\$ / \mathrm{s}]$ - particle speed;

$X[\$]$ - particle position;

$P[\$]$ - best position of the particle;

$G[\$]$ - best position of the group;

$\Delta \mathrm{t}[\mathrm{s}]$ - time step of each iteration, set as $1 \mathrm{~s}$;

$\omega$ [dimensionless] - coefficient of inertia;

$C_{I}$ [dimensionless] - cognitive coefficient;

$C_{2}$ [dimensionless] - social coefficient. 


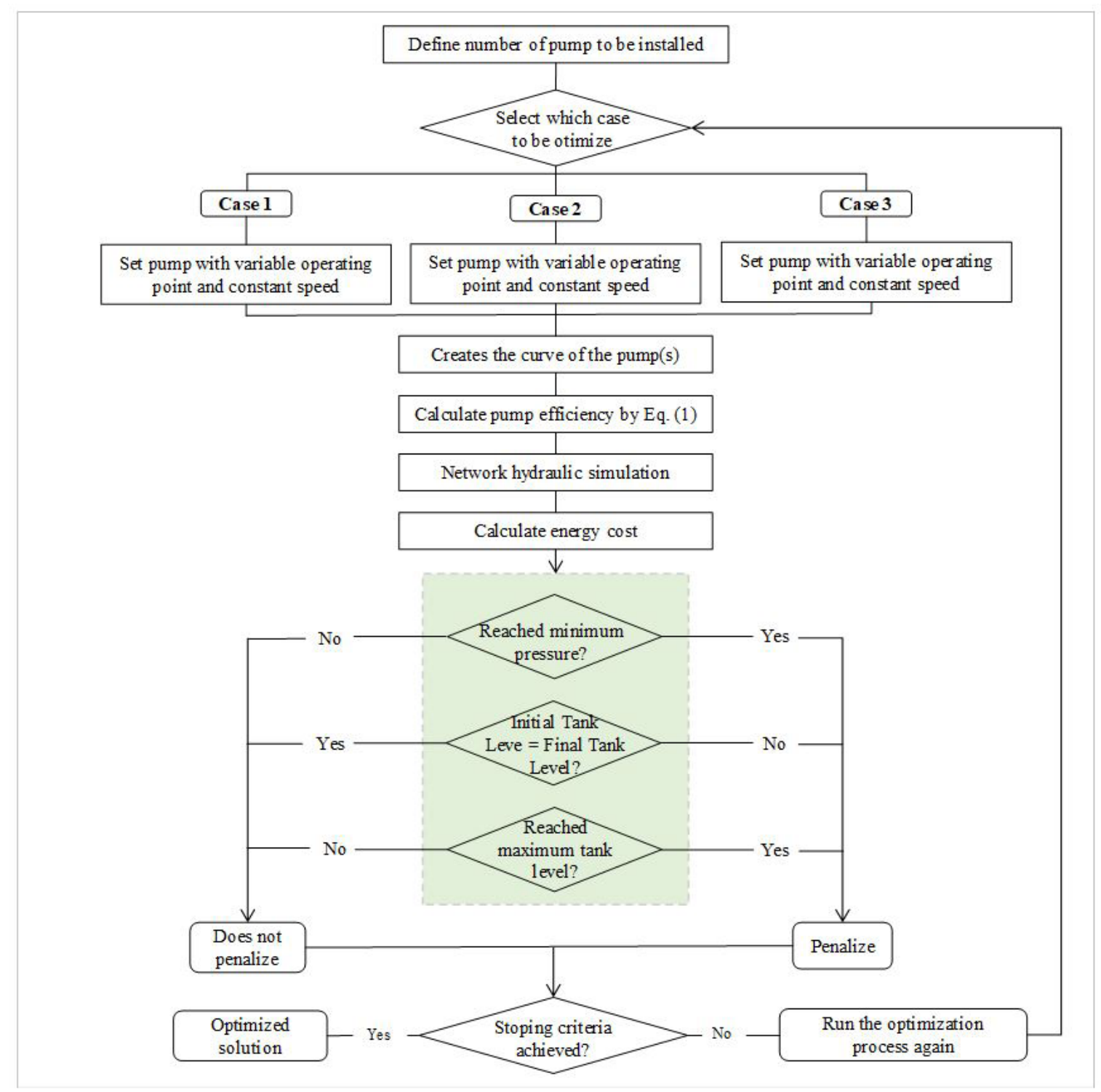

Figure 2. Flowchart of pump selection.

The decision variables used in the problem are the head $\left(\mathrm{H}_{\mathrm{BEP}}\right)$ and flow $\left(\mathrm{Q}_{\mathrm{BEP}}\right.$ of the pumps, and their rotational speed at each hour of operation. As presented by Beielstein et al. (2002) the dimensionless coefficients have important meanings. The coefficient of inertia represents the particle capacity to maintain its direction. The cognitive coefficient represents the particle memory, therefore using the particle best position it has ever been as a reference. Finally, the social coefficient represents the influence that the group of particles has, grouping the particles close to the best ones. In this case study, the default values provided by the MATLAB software were used: the coefficient of inertia was 1.1, the cognitive and social coefficients were 1.49 .

\section{CASE STUDY}

The case study is made in the Anytown network (Walski et al., 1987). This is a small network, with 40 pipes and 19 nodes, 16 of them with a demand ranging from 12.6 to $63.1 \mathrm{~L} / \mathrm{s}$, as shown in Figure 3.
The adopted values of restrictions are defined according to Brazilian standards (Brasil, 2010). The $10 \mathrm{~m}$ of minimum pressure guarantees the supply to consumers. The maximum levels of the tanks are established by the system and set to $10 \mathrm{~m}$, avoiding overflow. There is no minimum level, so the tanks can be emptied.

Three different scenarios are considered to evaluate the efficiency of the pumping station, where the number of pumps in parallel varied from one to three. In each scenario, the following three optimizations are made:

1) to optimize the operation point of the pumps $\left(\mathrm{Q}_{\mathrm{BEP}}\right.$ and $\left.\mathrm{H}_{\mathrm{BEP}}\right)$ considering fix speed;

2) to use the previous result of scenario 1 and optimize the rotational speed of the selected pump considering the use of speed driver;

3) optimize simultaneously the pump operation point and its rotational speed at each hour of the simulation.

For Cases 2 and 3 , when the pump is on, the relative rotational speed could not be less than 0.6 to avoid the operation at low 


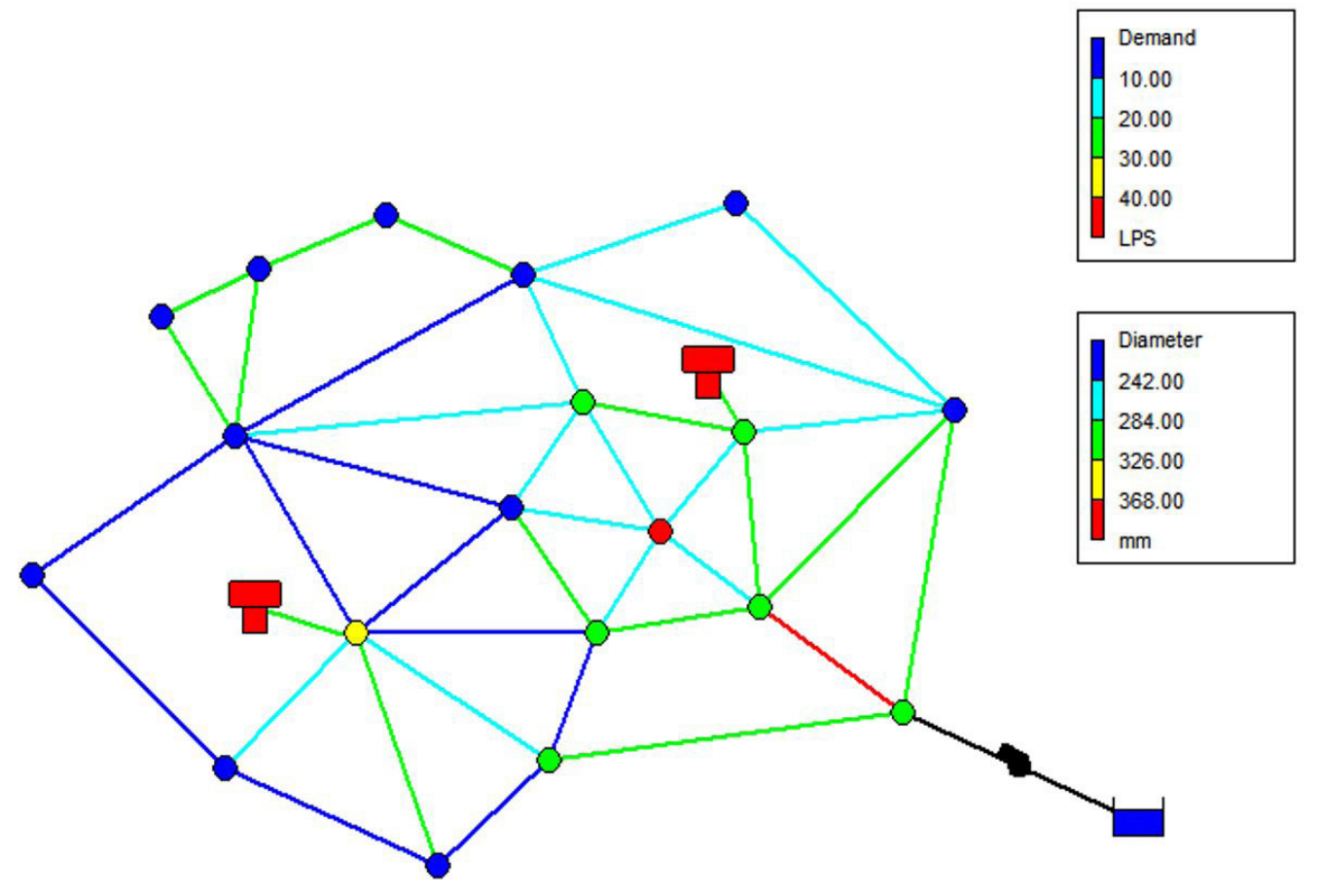

Figure 3. Anytown network layout.

Table 1. Standard values for energy and power tariffs.

\begin{tabular}{cc}
\hline Energy - non-peak $[\$ / \mathbf{k W h}]$ & $\mathbf{0 . 3 5 6 6 6}$ \\
\hline Energy -peak $[\$ / \mathrm{kWh}]$ & 0.53423 \\
Power - non-peak $[\$ / \mathrm{kW}]$ & 13.95 \\
Power -peak $[\$ / \mathrm{kW}]$ & 43.95 \\
\hline
\end{tabular}

efficiency, and mechanical and electrical problems that can occur at very low speeds (Lindstedt \& Karvinen, 2016). If so, the pump is switched off. Another important parameter to be considered is the energy tariff. Different values for the energy and power tariffs are adopted for the peak and non-peak hours. Table 1 presents the standard values, which were varied in a range of $\pm 50 \%$, with a $10 \%$ step, for a sensitivity analysis, totalizing ten different values for each tariff (power and energy). It is considered that energy and power tariffs could be differently changed, creating a total of 64 different scenarios of tariff. To reduce the computational effort, in these scenarios, the result obtained with the standard tariffs is used as a warm solution (Pasha \& Lansey, 2014). The energy tariff values used correspond to the tariffs applied by the energy concessionaire of the state of Minas Gerais, where the research was carried out. Thus, the feasibility of the proposed methodology could be evaluated for the study location.

\section{RESULTS AND DISCUSSIONS}

\section{Optimization}

Table 2 presents the results of the optimization processes for each Case Study, considering one, two or three pumps operating in parallel in each of them. It can be observed a reduction in energy costs, being the Case 3 the most economic. The presented reduction occurs because the conditions of Case 2 and 3 allow pumps to operate closer to their BEP. In addition, in Case 3 it is possible to precisely select the pump according to the hydraulic conditions of the network. The lowest cost obtained is achieved in the operation with two pumps in parallel. However, when evaluating the results in detail, it is observed that only one pump is operating during the $24 \mathrm{~h}$. This behavior is repeated for cases with three pumps.

Bearing it in mind, it can be concluded that increasing the number of pumps does not bring benefits to the water network. In the cases that presented two or three pumps in the system, the optimization process found the best results maintaining only one pump operating at all times. With only one larger size pump in the system, with higher flow, the performance is better, compared with two or three smaller pumps (Figure 1). Even operating sometimes far from BEP, this drop in efficiency is not enough significant to justify choosing more pumps. Thus, as the objective is to maintain the lowest energy cost, the algorithm kept only one pump.

Figure 4, shows the water demand curve of the system. It can be observed an increase from 6 am to $11 \mathrm{am}$, and then it steadily decreases until the end of the day. This behavior is important to understand some of the results obtained that will be shown next.

When evaluating the best results for the scenario with one pump operating, a similar behavior of pressure in network is observed for the three cases (Figure 5b), with a small increase of mean values, as shown in Table 3 . The difference can be explained by the operational strategy adopted in each case: in Case 1, the pump remains totally off for a longer period, and the system is supplied by the tanks. In Case 2 , the pump remains constantly on, 
Table 2. Results for the different pumping stations configuration and optimization procedures.

\begin{tabular}{|c|c|c|c|c|c|}
\hline & & & Case 1 & Case 2 & Case 3 \\
\hline \multirow[t]{3}{*}{ One pump } & Pump 1 & $Q_{B E P}\left[\mathrm{~m}^{3} / \mathrm{h}\right]$ & 506.10 & 506.10 & 429.86 \\
\hline & & $H_{B E P}[\mathrm{~m}]$ & 107.84 & 107.84 & 147.29 \\
\hline & & t [\$/day] & 12,198 & 8,412 & 7,716 \\
\hline \multirow[t]{5}{*}{ Two pumps } & Pump 1 & $Q_{B E P}\left[\mathrm{~m}^{3} / \mathrm{h}\right]$ & 305.90 & 305.90 & 338.17 \\
\hline & & $H_{B E P}[\mathrm{~m}]$ & 79.47 & 79.47 & 78.30 \\
\hline & Pump 2 & $Q_{B E P}\left[\mathrm{~m}^{3} / \mathrm{h}\right]$ & 810.36 & 810.36 & 543.00 \\
\hline & & $H_{B E P}[\mathrm{~m}]$ & 150.57 & 150.57 & 179.38 \\
\hline & & $\mathrm{t}$ [\$/day] & 12,266 & 6,107 & 4,844 \\
\hline \multirow[t]{7}{*}{ Three pumps } & Pump 1 & $Q_{B E P}\left[\mathrm{~m}^{3} / \mathrm{h}\right]$ & 577.17 & 577.17 & 486.65 \\
\hline & & $H_{B E P}[\mathrm{~m}]$ & 144.16 & 144.16 & 175.29 \\
\hline & Pump 2 & $Q_{B E P}\left[\mathrm{~m}^{3} / \mathrm{h}\right]$ & 420.42 & 420.42 & $1,734.60$ \\
\hline & & $H_{B E P}[\mathrm{~m}]$ & 120.25 & 120.25 & 33.37 \\
\hline & Pump 3 & $Q_{B E P}\left[\mathrm{~m}^{3} / \mathrm{h}\right]$ & 10.16 & 10.16 & $1,848.55$ \\
\hline & & $H_{B E P}[\mathrm{~m}]$ & 20.94 & 20.94 & 40.01 \\
\hline & & t [\$/day] & 15,973 & 9,731 & 9620 \\
\hline
\end{tabular}

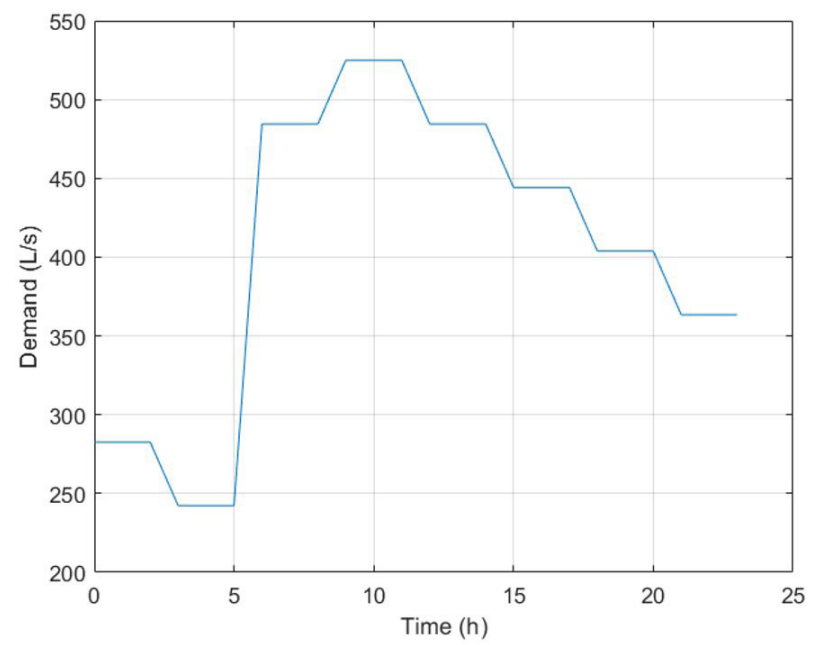

Figure 4. Water Demand Curve for a typical day.

Case 1

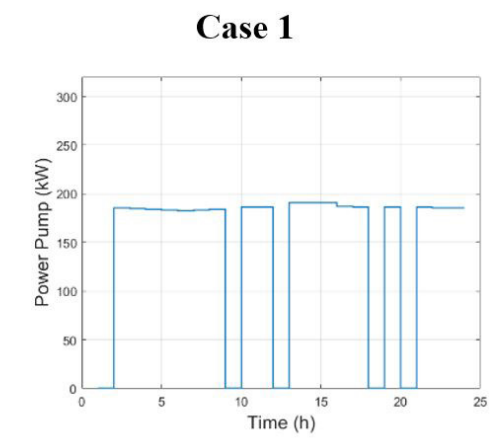

(a)

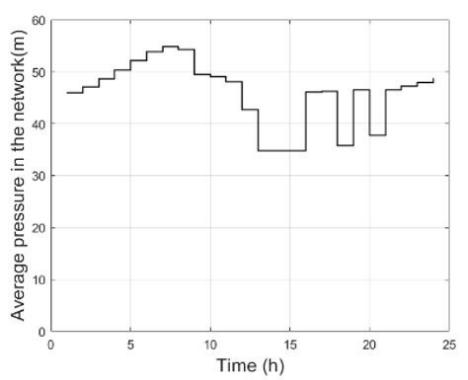

Case 2
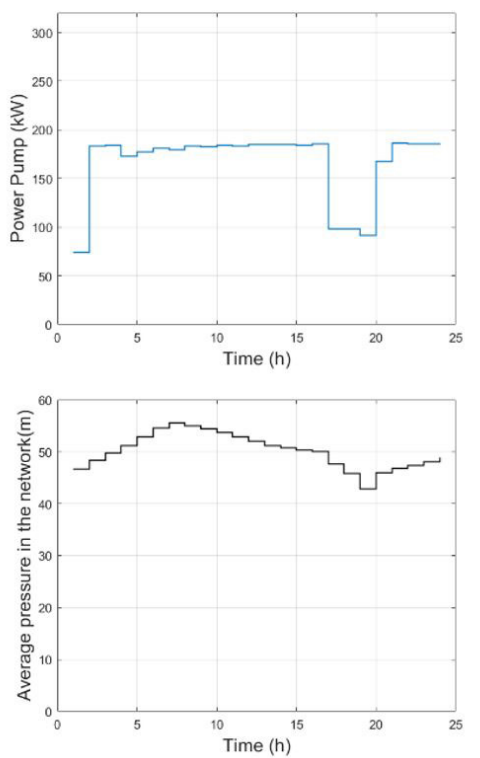

Case 3
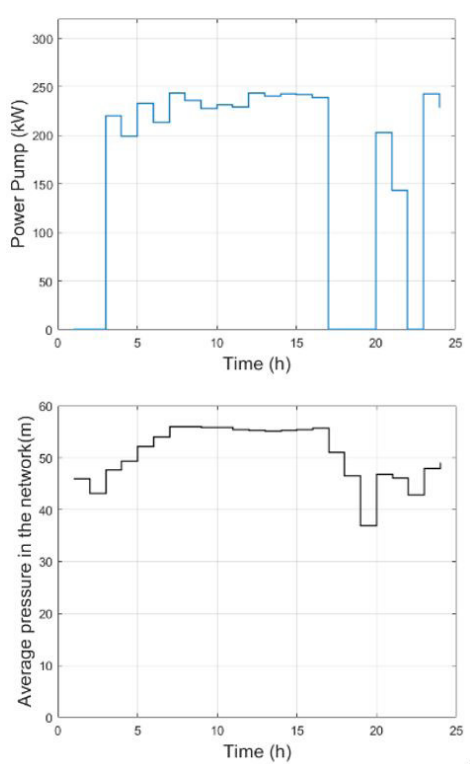

Figure 5. Results using one pump: (a) Pump power; (b) Average pressure in the network. 
only reducing the speed during peak hours, making the pressure in network to be more constant. It is important to be observe in Case 2 that, despite having the highest consumption of total energy among all cases, the reduction of consumption and demand during peak hour generated an economic benefit to the system when comparing with Case 1. Lastly, the mean pressure of the Case 3 is close to the Case 2, due to the greater $H_{B E P}$ of the selected pump, necessary to maintain the tanks full until peak hours, period when the pump is completely switched off. Compared to Case 1, the total energy consumption is $9.95 \%$ higher for Case 2 and 3.86\% higher for Case 3, but the economic benefit obtained with the interruption of the operation during peak hour is great: a $45 \%$ reduction of costs from Case 1 to Case 2, and 58\% from Case 1 to Case 3. It is observed that the power demand outside peak hours in Case 3 is the highest among all cases, precisely so that is possible to operate the selected large pump.

Figure 5b shows that until $9 \mathrm{am}$, in all cases, the pressure showed similar behaviors with constant increase, since due to the low water consumption in this period, the head losses in the system are reduced. From 9 am onwards, each case showed a specific behavior, being attributed both to the demand values and the operation of pumps.

It is important to mention, that a pressure control need to be done to contain the water leaks in the networks, as shown by Nicolini \& Zovatto (2009). As in this work leakages are not

Table 3. Mean Network Pressure, Demand and Consumption in peak hour and regular hour.

\begin{tabular}{lrrr}
\hline & Case 1 & Case 2 & Case 3 \\
\hline Average Network Pressure $(\mathrm{m})$ & 46.00 & 50.11 & 50.62 \\
Demand peak hour $(\mathrm{kW})$ & 186.70 & 98.58 & 0.00 \\
Consumption peak hour $(\mathrm{kWh})$ & 373.08 & 288.67 & 0.00 \\
Average Consumption peak hour (kWh) & 124.36 & 96.22 & 0.00 \\
Demand regular hour $(\mathrm{kW})$ & 191.07 & 186.26 & 243.46 \\
Consumption regular hour (kWh) & $3,535.86$ & $4,009.22$ & $4,059.83$ \\
Average Consumption regular hour $(\mathrm{kWh})$ & 147.33 & 167.05 & 169.16 \\
Total Consumption [kWh/day] & $3,908.94$ & $4,297.89$ & $4,059.83$ \\
\hline
\end{tabular}

considered, the slightly higher pressure values did not penalized the total operational costs, which could be an important parcel in pump selection, depending on the network leakage index.

Another point to be discussed is the oscillation of tanks' level according to the operational strategy adopted in each case (Figure 6). For Case 1, the tanks' levels increase quickly in the early hours of the day, and are unable to maintain the level, emptying soon thereafter. It is observed that emptying of tanks starts at the time of highest demand (Figure 4), and it is noted that at the same time the pump is turned off. Different of other cases, the pump needs to be switched on during one hour of peak hour, because the tanks are empty. Thus, if the pump are not switched on, there would be an insufficient water supply.

The behavior of Case 2 also shows the filling of tanks in the early hours of the day and a gradual emptying until reaching zero during peak hours. In this case there is no shutdown of the pump, only changes in its rotational speed, justifying a smoother reduction in the level of the tanks. The advantages of this case is the operation of pumps during the peak hour with reduced power. This scenario leads to a significantly decrease in energy consumption and power demand, unlike Case 1, where, despite being off for a short period, there is a need for its operation at full power to meet the water demand.

Finally, in Case 3, the tanks also filled quickly in the early hours of the day, but remained full for a long period, emptying only during peak hours when the pump was switched off. It is noted in this case that the pump power presented higher values most party of the day, from 3 am to 4 pm, providing a higher flow, higher than demand of the period, which allows the filling of the tanks. In one hand, this behavior can generate a higher energy consumption, on the other hand, the pump can be turned off for all peak hours, where the energy tariff is high. If compared to Case 1, energy consumption is $3.86 \%$ higher, however, due to the operation imposed on the pump, the values with energy costs in Case 3 showed a 58\% reduction. This was allowed by optimization because the tanks were full, having the capacity to supply the network during the peak hours period.
Case 1

(a)

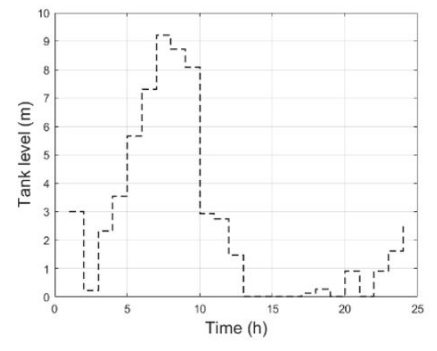

(b)

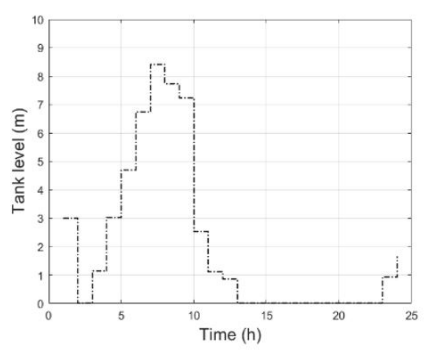

Case 2
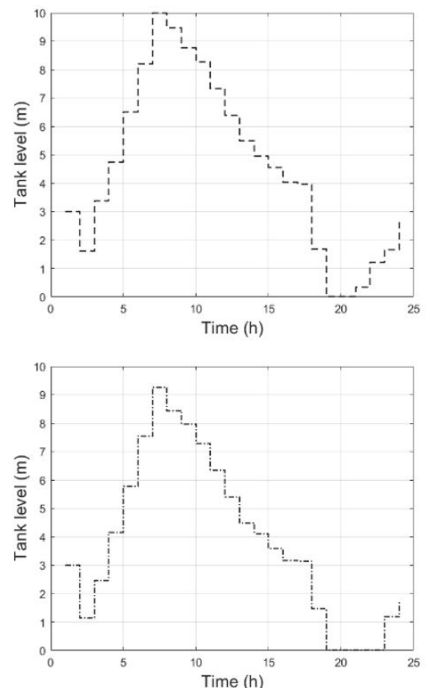

Case 3
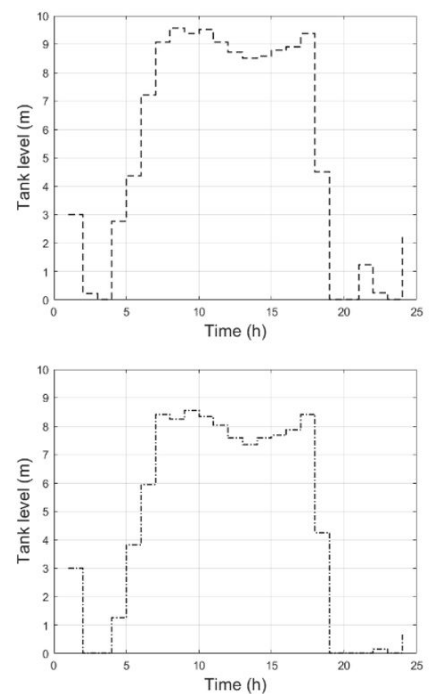

Figure 6. Tanks level: (a) Tank 1; (b) Tank 2. 


\section{Sensitivity analysis}

The results of the presented optimization process are generated using energy and power tariffs specified in the case study. However, for a better understanding of tariffs' effects in optimization of pump operation and selection, a sensitivity analysis is made to Case 3 with one pump. In this context, 64 scenarios with different tariff values are evaluated. The values are defined combining the variation of tariff in peak hour and non-peak hour, between 25 to $200 \%$ of the standard value.

The results can be analyzed in Figure 7, which presents the relation between tariff values with pump head and flow. It is noted in Figure $7 \mathrm{a}$ that $H_{B E P}$ tends to increase with tariff values. Larger

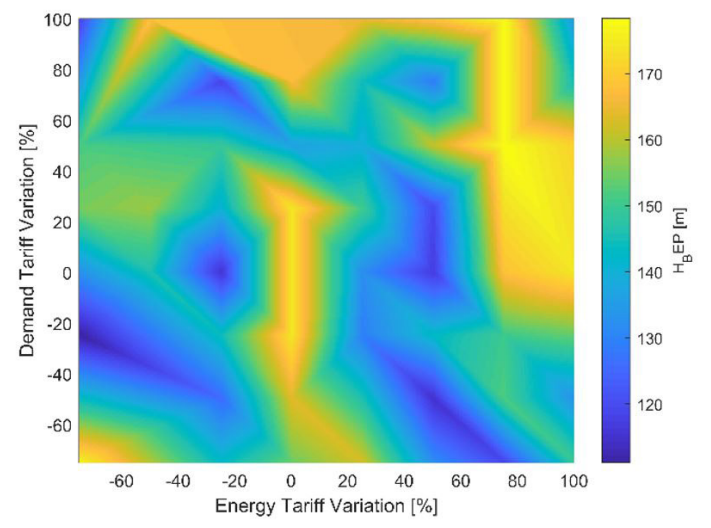

(a)

Figure 7. Demand Tariff Variation: (a) HBEP; (b) QBEP.

Tank 1

(a)

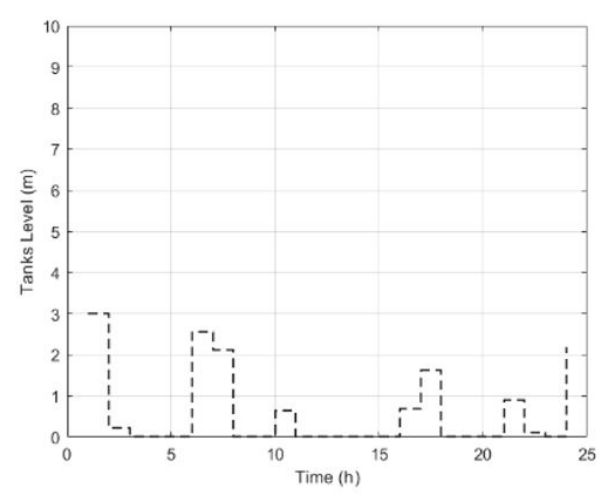

Tank 1

(b)

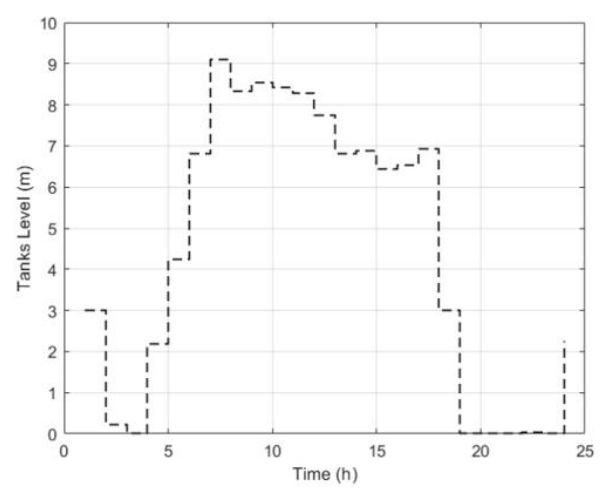

$H_{B E P}$ allows tanks to fill faster and the pump to stop operating at peak hours. The reduction in tariffs allows the pump to operate for longer period without great costs.

Figure $7 \mathrm{~b}$ shows the behavior of $Q_{B E P}$ as tariffs change. It is noticed that the flow also tends to increase when the tariff values increase. Like $H_{B E P}$, increasing $Q_{B E P}$ results in greater amount of water supplied to the system, thus being able to fill the reservoirs faster, trying to avoid the operation during peak hours. In addition, as shown in Figure 2, pumps with higher flow rates presents better efficiency, a factor even more relevant in this scenario of high energy tariffs.

Finally, corroborating with the results' analysis, Figure 8 shows the tank level during the day. For the case with lowest tariffs, the

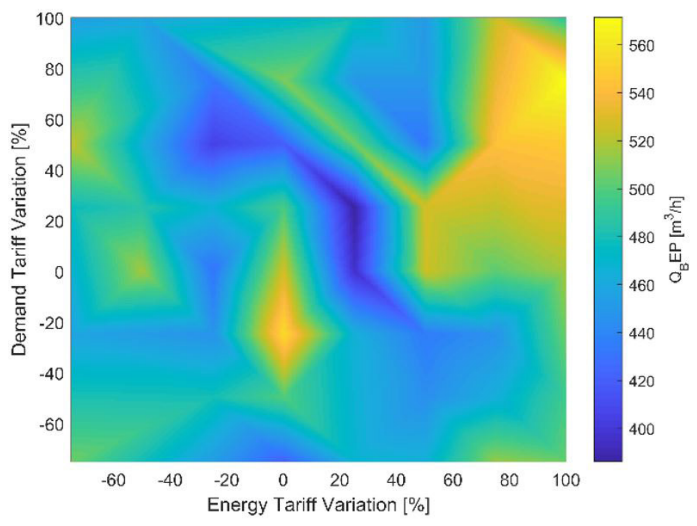

(b)

Tank 2

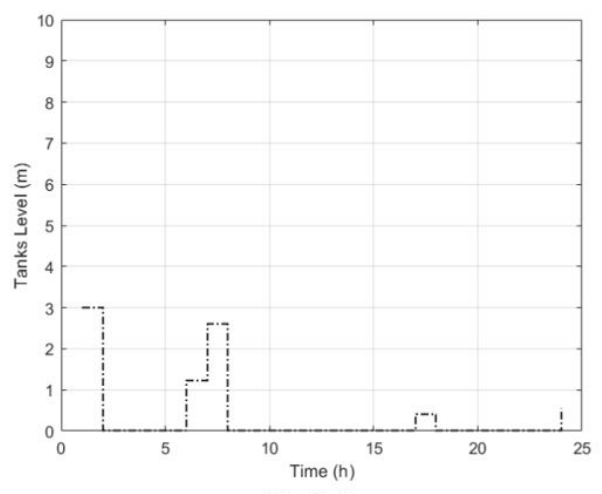

Tank 2

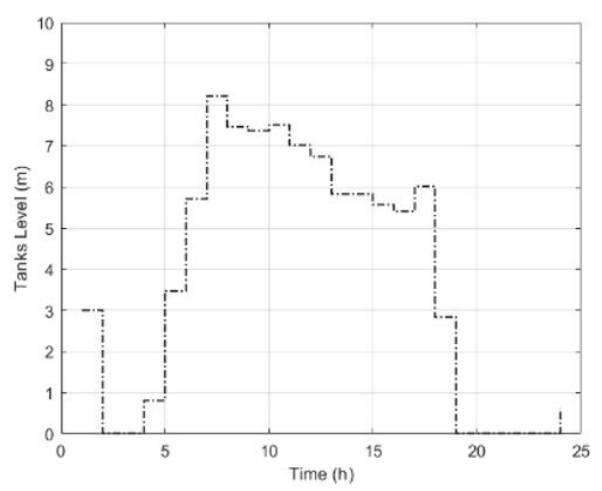

Figure 8. Tanks level: (a) Minimum Tariff 1; (b) Maximum Tariff. 
tanks' levels are always low due to the low cost of tariffs, which allows the pump to stay on for longer periods. In the case of maximum tariffs, it is noted that tanks remained full along the day, emptying during peak hours, as the pumps were turned off. The tank level analysis confirms the need of pumps with higher power in these cases so that their operation is avoided during peak hours.

\section{CONCLUSIONS}

Pumps' operation must be carefully analyzed to avoid excessive energy costs or that important operational issues, such as maintaining operational pressures, are compromised. The work aimed to evaluate the benefits that an optimized pump selection can bring.

In the presented case study, the use of more than one pump operating in parallel did not presented economic benefits, since the optimization processes carried out kept only one pump operating, even for cases where more than one pump was available. Despite this, from an operational point of view, the use of only one pump can generate excessive wear of the pump and can let the network without supply in case of mechanical failure.

However, a single pump operating correctly can generate significant energy gains. The study case presented showed that the form the pump is operated can bring high benefits. The Case 1 compared to Case 3, presented 60\% more energy expenditure. Comparing Case 2 to Case 3, the reduction in expenses was $42 \%$. Thus, maintaining a more flexible operational routine, and selecting precisely the pump according to the network conditions, can bring greater energy efficiency.

The tanks' levels are important to define the operational schedule of pumps, since they allow them to stop during peak hours, when the energy tariff is higher. It is also observed through the sensitivity analysis that the tanks are especially important during peak hours, since the behavior of the water level can vary widely depending on the tariff in the region. This because, high tariffs favor the filling of tanks and low tariffs can make the installation of tanks less relevant.

Thus, further studies are recommended, with the possibility of using more tanks, analyzing not only the operation of the pumps, but also the average costs of implantation and operation of new tanks. The importance of further studies on the operation of pumping stations is also emphasized, which analyzes, in addition to the selection of pumps, the identification of their location in the water distribution network.

\section{ACKNOWLEDGEMENTS}

This study was financed in part by the Conselho Nacional de Desenvolvimento Científico e Tecnológico (CNPq).

\section{REFERENCES}

American National Standards Institute - ANSI. (1994). ANSI/ HI1.1-1.5: American National Standard for Centrifugal Pumps (pp. 71). Washington: ANSI.
Beielstein, T., Parsolpoulos, K., \& Vrahatis, M. (2002). Tuning PSO parameters through sensitivity analysis. Dortmund: Universität Dortmund. http://dx.doi.org/10.17877/DE290R-15305.

Boulos, P. F., Wu, Z., Orr, C. H., Moore, M., Hsiung, P., \& Thomas, D. (2001). Optimal pump operation of water distribution systems using genetic algorithms. In Proceedings of the Distribution System Symposium. San Diego: AWWA.

Brasil. Instituto Nacional de Metrologia, Normalização e Qualidade Industrial - INMETRO. (2010, 28 de setembro). Portaria $n^{\circ}$ 455, de 01 de dezembro 2010. Requisitos de Avaliação Da Conformidade para Bombas e motobombas centrífugas. Diário Oficial da União, Brasília.

Brentan, B., Meirelles, G., Luvizotto Junior, E., \& Izquierdo, J. (2018). Joint operation of pressure-reducing valves and pumps for improving the efficiency of water distribution systems. Journal of Water Resources Planning and Management, 144(9), 04018055. http:/ / dx.doi.org/10.1061/(ASCE)WR.1943-5452.0000974.

Brentan, B., \& Luvizotto, E. (2014) Refining OSO applied to electric energy cost reduction inwater pumping. Water Research and Management, 4(2), 19-30.

Eberhart, R., \& Kennedy, J. (1995). New optimizer using particle swarm theory. In Proceedings of the International Symposium on Micro Machine and Human Science (pp. 39-43). USA: IEEE. http:/ / dx.doi. org/10.1109/MHS.1995.494215.

European Comission - EC. (2003). European guide to pump efficiency for single stage centrifugal pumps. Brussels: EC.

Giacomello, C., Kapelan, Z., \& Nicolini, M. (2013). Fast hybrid optimization method for effective pump scheduling. Journal of Water Resources Planning and Management, 139(2), 175-183. http:/ / dx.doi.org/10.1061/(ASCE)WR.1943-5452.0000239.

Hashemi, S. S., Tabesh, M., \& Ataeekia, B. (2014). Ant-colony optimization of pumping schedule to minimize the energy cost using variable-speed pumps in water distribution networks. Urban Water Journal, 11(5), 335-347. http://dx.doi.org/10.1080/15730 62X.2013.795233.

Hydraulic Institute. (1994). Hydraulic institute standards for centrifugal. Rotary \& Reciprocating Pumps. Parsippany: Hydraulic Institute.

International Electrotechnical Commision (2008). Rotating electrical machines-part 30: efficiency classes of single-speed, three-phase, cage-induction motors (IE-Code). PN-EN 60034-30. Warsaw, Polônia: Polski Komitet Normalizacyjny.

Jowitt, P. W., \& Germanopoulos, G. (1992). Optimal pump scheduling in water-supply networks. Journal of Water Resources Planning and Management, 118(4), 406-422. http://dx.doi.org/10.1061/ (ASCE)0733-9496(1992)118:4(406). 
Koor, M., Vassiljev, A., \& Koppel, T. (2014). Optimal pump count prediction algorithm for identical pumps working in parallel mode. Procedia Engineering, 70, 951-958. http://dx.doi.org/10.1016/j. proeng.2014.02.106.

Lindstedt, M., \& Karvinen, R. (2016). Optimal control of pump rotational speed in filling and emptying a reservoir: minimum energy consumption with fixed time. Energy Efficiency, 9(6), 14611474. http://dx.doi.org/10.1007/s12053-016-9434-y.

Mala-Jetmarova, H., Sultanova, N., \& Savic, D. (2018). Lost in optimisation of water distribution systems? A literature review of system design. Water, 10(3), 307-410. https://doi.org/10.3390/ w10030307.

Manzi, D., Goulart, T. D. C., Brentan, B. M., Lima, G. M., \& Luvizotto Junior, E. (2018). Dimensionamento ótimo de redes de distribuição de água com uso de métodos de otimização inspirados na natureza. Revista DAE, 66(212), 16-31. http:// dx.doi.org/10.4322/dae.2018.020.

Nicolini, M., \& Zovatto, L. (2009). Optimal location and control of pressure reducing valves in water network. Journal of Water Resources Planning and Management, 135(3), 178-187. http:/ /dx.doi. org/10.1061/(ASCE)0733-9496(2009)135:3(178).

Olszewski, P. (2016). Genetic optimization and experimental verification of complex parallel pumping station with centrifugal pumps. Applied Energy, 178, 527-539. http://dx.doi.org/10.1016/j. apenergy.2016.06.084.

Pasha, M., \& Lansey, K. (2014). Strategies to develop warm solutiong for real-time pump scheduling for water distribution systems. Water Resources Management, 28(12), 3975-3987. http:/ / dx.doi.org/10.1007/s11269-014-0721-0.

Rossman, L. A. (2000). EPANET 2.0 User's Manual. USA: Drinking Water Research Division, Risk Reduction Engineering Laboratory, U.S. Environmental Protection Agency.

Stoffel, B., \& Lauer, J. (1994). Theoretically attainable efficiency of centrifugal pumps. VDMA project-final report. Darmstadt: Technical University of Darmstadt.
Tang, Y., Zheng, G., \& Zhang, S. (2014). Optimal control approaches of pumping stations to achieve energy efficiency and load shifting. International Journal of Electrical Power \& Energy Systems, 55, 572-580. http://dx.doi.org/10.1016/j.ijepes.2013.10.023.

Tarquin, A. J., \& Dowdy, J. (1989). Optimal pump operation in water distribution. Journal of Hydraulic Engineering, 115(2), 158-168. http://dx.doi.org/10.1061/(ASCE)0733-9429(1989)115:2(158).

Venkatesh, G., \& Brattebø, H. (2011). Energy consumption, costs and environmental impacts for urban water cycle services: case study of Oslo (Norway). Energy, 36(2), 792-800. http://dx.doi. org/10.1016/j.energy.2010.12.040.

Walski, T. M. (1993). Tips for saving energy in pumping operations. Journal - American Water Works Association, 85(7), 49-53. http:// dx.doi.org/10.1002/j.1551-8833.1993.tb06023.x.

Walski, T. M., Brill Junior, E. D., Gessler, J., Goulter, I. C., Jeppson, R. M., Lansey, K., Lee, H.-L., Liebman, J. C., Mays, L., Morgan, D. R., \& Ormsbee, L. (1987). Battle of the network models: epilogue. Journal of Water Resources Planning and Management, 113(2), 191-203. http://dx.doi.org/10.1061/(ASCE)0733-9496(1987)113:2(191).

Zhang, H., Xia, X., \& Zhang, J. (2012). Optimal sizing and operation of pumping systems to achieve energy efficiency and load shifting. Electric Power Systems Research, 85, 41-50. http:// dx.doi.org/10.1016/j.epsr.2011.12.002.

\section{Authors contributions}

Débora Salomé Móller: Performed the methodology, obtained the results and wrote the text.

Gustavo Meirelles Lima: Performed the methodology and revised the results and text.

Bruno Melo Brentan: Contributed with technical notes and revised the text.

Daniel Bezerra Barros: Contributed with technical notes and revised the text. 